\title{
Changes in Glucose-6-phosphate Dehydrogenase Activity in Paroxysmal Atrial Fibrillation
}

\begin{abstract}
Keywords
Paroxysmal atrial fibrillation; Glucose-6-phosphate dehydrogenase: Antioxidant defense system

Abstract

Background: The antioxidant defense system has been subject to investigations in various cardiovascular diseases. The studies of its status in paroxysmal atrial fibrillation are scarce. The enzyme glucose-6phosphate dehydrogenase is the main source of reducing equivalents and its activity is crucial for the antioxidant defense system of the cell.

Purpose: To study the activity of glucose-6-phosphate dehydrogenase in dynamics as an indicator of the antioxidant defense system in patients with paroxysmal atrial fibrillation ( $<48$ hours).
\end{abstract}

Patients and methods: The enzyme was studied in erythrocytes of 51 patients $(59.84 \pm 1.60,26$ males) immediately after hospitalization, 24 hours and 28 days after sinus rhythm restoration. It included also 52 healthy controls $(59.50 \pm 1.46,26$ males), matching the patients by gender and age. The rhythm regulation was achieved by propafenone. The enzyme activity was determined spectrophotometrically.

Results: The mean duration of atrial fibrillation episodes prio to hospitalization was 8.1 hours, the majority of the patients being hospitalized on the $5^{\text {th }}$ hour from the arrhythmia onset. Upon admission, the patients' enzyme activity was lower as compared to the controls $\left(2.50 \pm 0.10\right.$ vs $\left.2.90 \pm 0.15 \mathrm{nmol} \mathrm{NADP}^{+} \mathrm{min} / \mathrm{mg} \mathrm{Hb}, \mathrm{p}<0.05\right)$. The difference was retained for twenty-four hours after rhythm regulation $(2.41 \pm 0.09$ vs $\left.2.90 \pm 0.15 \mathrm{nmol} \mathrm{NADP}^{+} \mathrm{min} / \mathrm{mg} \mathrm{Hb}, \mathrm{p}<0.05\right)$. On the twenty-eighth day there was no significant difference $(2.63 \pm 0.08$ vs $2.90 \pm 0.15 \mathrm{nmol}$ NADP $\mathrm{min} / \mathrm{mg} \mathrm{Hb}, \mathrm{p}>0.05$ ).

Conclusion: In the early hours of its clinical manifestation paroxysmal atrial fibrillation is associated with reduced glucose-6phosphate dehydrogenase activity, which persists after sinus rhythm restoration and is slowly increased with time. In essence, the changes in enzyme activity reflect changes in antioxidant defense system. Furthermore, the specific dynamic is suggestive of close relation to the rhythm disorder. Future studies would allow for determination of the precise role of the antioxidant defense system in the disease pathogenesis as well as its significance for the disease prevention and treatment.

\section{Introduction}

It is known that the changes in the oxidant status of the organisms play a significant role in the pathogenesis of a number of cardiovascular diseases [1-4]. The reactive oxygen species have a bearing on the development of endothelial dysfunction, the rupture of atherosclerotic plaques, the manifestation of heart failure, hemorrhagic stroke, etc. [5-7].

The paroxysmal atrial fibrillation (PAF) is one of the five types of atrial fibrillation according to its clinical presentation and duration. Although AF paroxysms may continue up to 7 days, clinically important are the first 48 hours which allow for acute regulation of the rhythm. PAF comprises between $25 \%$ and $62 \%$ of all cases of atrial fibrillation (AF) [8], the risk of stroke and thromboembolic

\section{Journal of}

\section{Cardiobiology}

Mariya Negrinova Negreva ${ }^{1 *}$, Atanas Penev Penev $^{1}$, Svetoslav Jivkov Georgiev ${ }^{2,3}$ and Albena Alexandrova Alexandrova ${ }^{4}$

${ }^{1}$ First Clinic of Cardiology, Varna University Hospital "St Marina”, Hristo Smirnenski, 1, 9000 Varna, Bulgaria

${ }^{2}$ Second Clinic of Cardiology, Varna University Hospital "St Marina”, Hristo Smirnenski, 1, 9000 Varna, Bulgaria

${ }^{3}$ Department of Internal Medicine, Medical University of Varna, Varna, Bulgaria

${ }^{4}$ Institute of Neurobiology at Bulgarian Academy of Sciences, Sofia, Bulgaria

\section{*Address for Correspondence}

Mariya Negrinova Negreva, MD, First Clinic of Cardiology, Varna University Hospital "St Marina", Hristo Smirnenski, 1, 9000 Varna Bulgaria, Tel: +359 888487 303; Fax: +359 52302 881; E-mail: mnegreva@abv.bg

Copyright: ( 2014 Negreva MN, et al. This is an open access article distributed under the Creative Commons Attribution License, which permits unrestricted use, distribution, and reproduction in any medium, provided the original work is properly cited.

Submission: 10 December, 2013

Accepted: 02 January, 2014

Published: 07 January, 2014

incidences being similar to that in persistent and permanent AF [9]. The high morbidity, the usually progressive course of the disease and the frequent complications are the reasons for the numerous studies in search of the mechanisms participating in the arrhythmia triggering and maintenance.

The literary data increasingly suggest the potential role of the oxidative stress in the AF pathogenesis [10-13]. The studies focus mainly on permanent $\mathrm{AF}$ and the patients comprise a heterogeneous population with comorbidities associated with antioxidant disorders [14-17]. There are singular studies on the condition of the oxidant and antioxidant system in PAF, the data being based primarily on experimental models and the indicators of the oxidative status are most frequently studied at a single moment $[11,18,19]$.

Glucose-6-phosphate dehydrogenase (Glu-6-PhD) is the first and rate-limiting enzyme from the pentose phosphate pathway (PPP) of all cells in the human organism. It catalyzes the synthesis of riboses which are necessary for the nucleic acid production (Figure 1). The

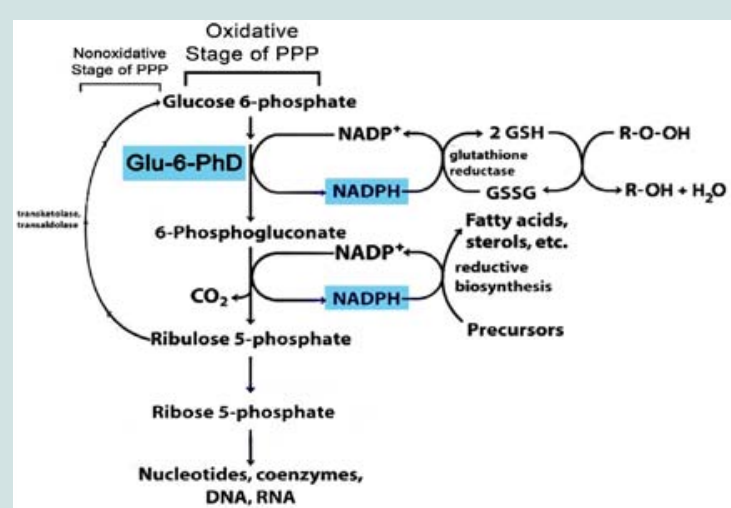

Figure 1: Role of glucose-6-phosphate dehydrogenase for the synthesis of riboses and NADPH in the cell 
Citation: Negreva MN, Penev AP, Georgiev SJ, Alexandrova AA. Changes in Glucose-6-phosphate Dehydrogenase Activity in Paroxysmal Atrial Fibrillation. J Cardiobiol. 2014;2(1): 5.

enzyme is a main source of NADPH, which, in its turn, is needed for the recovery of the reduced form of the important non-enzyme antioxidant glutathione (GSH) [20]. GSH prevents the oxidative damage of the nucleic acids, lipids and proteins by neutralizing directly the physiological and pathologically generated active oxygen forms. The GSH levels in the cell have a direct dependence on the levels of NADPH, thus making the non-enzyme antioxidant defense strongly dependent on Glu-6-PhD [21].

On the other hand, the experimental studies indicate that NADPH directly stimulates the catalytic center of one of the most important antioxidant enzyme catalase [22]. It converts the hydrogen peroxide into water and prevents the formation of highly reactive hydroxyl radicals with a powerful oxidative potential.

The NADPH, obtained as a result of the catalytic action of Glu6- $\mathrm{PhD}$, influences both the non-enzyme and the enzyme antioxidant system [22]. This determines Glu-6-PhD as a key "defensive" enzyme for all cells [23]. Changes in its activity are associated with changes in the antioxidant system. It is the only NADPH-producing enzyme whose activity changes rapidly under conditions of oxidative stress [24].

The above facts were determining for the formulation of the purpose of our study.

\section{Purpose}

To study the dynamics of the Glu-6-PhD activity as an indicator of the antioxidant defense system in patients with paroxysmal atrial fibrillation ( $<48$ hours).

\section{Patients and Methods}

\section{Patients}

The study was conducted in the Intensive Cardiology Unit of $1^{\text {st }}$ Clinic of Cardiology at University Hospital "St. Marina"- Varna for the period from October 2010 to May 2012 after the approval of the Scientific Research Ethics Commission at the above hospital and in accordance with the requirements of the Helsinki Declaration [25].

A total of 338 patients with $\operatorname{PAF}(<48$ hours) were screened to the study. Because of accompanying diseases, intake of some medicaments and/or inability to precisely specify the arrhythmia onset, 259 patients dropped out of the study (cf exclusion criteria). A criterion for determining the time span of rhythm disorder was the patients' detailed case history, in which they determined the beginning of the episode of atrial fibrillation on the basis of a subjective sensation of 'palpitation'. The electrocardiographic investigation performed immediately after hospitalization and the screen monitoring were used to confirm the diagnosis.

For sinus rhythm restoration propafenone was administered to the rest of the patients ( 79 patients) according to the established scheme, namely i.v. $2 \mathrm{mg} / \mathrm{kg}$ bolus, followed by infusion in a dose 0.0078 $\mathrm{mg} / \mathrm{kg} / \mathrm{min}$ per $120 \mathrm{~min}$. In cases of persistent rhythm disorder, the treatment with propafenone was continued p.o. in a dose of $300 \mathrm{mg}$ three times daily in an interval of 8 hours $[26,27]$. The total duration of the used scheme for the sinus rhythm recovery with propafenone was a maximum of 24 hours, within which sinus rhythm was registered in 56 participants in the study ( 31 men, 25 women). Until the end of the study (28 days after rhythm restoration) all the 56 patients took p.o. propafenone $150 \mathrm{mg}$ three times daily as maintenance dose. No recurrences of PAF were observed till the end of the study.

After equalization of the patients' group in terms of gender structure, 51 patients were selected to the study, mean age $59.84 \pm 1.60$ years (31-77 years) of whom 26 male (50.9\%) and 25 female (49.1\%).

So far, there have been no literary data about the effect of propafenone on the oxidant status of patients with paroxysmal atrial fibrillation. Our preliminary studies, conducted in vitro, did not establish an antioxidant effect of the medication either.

The control group was formed as identical to that of the patients' in terms of gender, age, accompanying diseases and body mass index (BMI) in order to eliminate their influence on our results. A total of 169 controls were screened to the study, of which 52 were selected to the study. The mean age of the controls was $59.50 \pm 1.46$ years $(30-76$ years), the males and females being of equal number 26 (50\%). Up to this point of the study, the investigated controls had not reported history or electrocardiographic data for registered AF episodes.

The following exclusion criteria for the study participation were used:

1. Cardiovascular diseases, namely: ischemic heart disease (myocardial infarction, acute coronary syndrome or coronary revascularization - PCI/CABG, angina pectoris); chronic heart failure; uncontrollable hypertension; implanted device for the treatment of rhythm-conducive disorders; inflammatory heart diseases - myocarditis, pericarditis, infectious endocarditis, congenital valvular defects; moderate or severe acquired valvular defects; cardiomyopathies.

2. Other diseases - chronic renal failure; diseases of the central nervous system; inflammatory and/or infectious diseases for the previous three months; neoplasmic diseases; autoimmune diseases; chronic pulmonary diseases; liver insufficiency; diseases of the endocrine nervous system (except for diabetes mellitus type 2, non-insulin dependent, well controlled).

3. Intake of hormone-replacement therapy or contraceptives; systematic intake of analgesics, incl. non-steroidal antiinflammatory drugs.

4. Inability to precisely specify the arrhythmia onset.

5. Persistence of the arrhythmia after the 24 hours' scheme of propafenone; converting PAF by electrical cardioversion; recurrence of the atrial fibrillation, after sinus rhythm restoration;

The same exclusion criteria were applied both to the patients and the controls.

\section{Obtaining erythrocytes: determination of Glu-6-PhD activity}

Blood samples were taken from the patients with PAF three times, e.g. immediately after their hospitalization in the ward, as well as on the $24^{\text {th }}$ hour and on the $28^{\text {th }}$ day after the restoration of the sinus rhythm. The investigation of the Glu-6-PhD activity on the twentyeighth day was determined by means of a preliminary investigation. Blood samples were taken from the controls once.

The Glu-6-PhD activity was determined in the erythrocytes obtained in $4 \mathrm{ml}$ venous blood collected in a heparin vacutainer 
Citation: Negreva MN, Penev AP, Georgiev SJ, Alexandrova AA. Changes in Glucose-6-phosphate Dehydrogenase Activity in Paroxysmal Atrial Fibrillation. J Cardiobiol. 2014;2(1): 5.

(Vacuette/4.0 $\mathrm{ml} / \mathrm{Li} \mathrm{Hep).} \mathrm{The} \mathrm{blood} \mathrm{was} \mathrm{centrifuged} \mathrm{at} 600 \mathrm{~g}$ for $10 \mathrm{~min}$. The obtained plasma was discarded, the erythrocytes were washed in $1 \mathrm{ml}$ normal saline $(0.9 \% \mathrm{NaCl})$, centrifuged again under the above conditions and the supernatant was removed. The erythrocyte washing was performed twice. The resultant erythrocyte suspension was frozen at $-70{ }^{\circ} \mathrm{C}$ and stored at this temperature for up to six months. A 5\%-erythrocyte suspension was used for the investigation of the indicators in the erythrocytes.

The enzyme activity was determined by the method of Cartier et al. [28] in a reaction environment, containing $100 \mathrm{MM}$ potassium phosphate buffer, $5 \mathrm{mM}$ glucose-6-phosphate and $0.5 \mathrm{MM} \mathrm{NADP}{ }^{+}$, the reduction of $\mathrm{NADP}^{+}$being measured spectrophotometrically in $340 \mathrm{~nm}$. The enzyme activity was calculated in $\mathrm{nmol} / \mathrm{min} / \mathrm{mg} \mathrm{Hb}$ at a molar extinction coefficient $6.22 \times 10^{6} \mathrm{M}^{-1} \mathrm{~cm}^{-1}$. Each specimen was examined three times, the results being with high degree of repeatability, and the mean value of them was taken in consideration.

\section{Statistical analysis of the results}

The statistical processing of the results was carried out by means of software product GraphPad Prism 4. Descriptive statistics was used for the calculation of indicators of relative share, mean values, standard error of the mean (SEM) and central tendency mode (Mo). Analysis of the hypotheses was made through Student's t-criterion for comparing mean values and indicators of relative share at reliability a level 0.95 (values $\mathrm{p}<0.05$ are considered statistically significant).

The results were presented as a mean value \pm SEM arithmetic $(\bar{x} \pm S \bar{x})$.

\section{Results}

\section{Indicators, characterizing the participants in the study}

In terms of number of participants, mean age and gender structure, the group of the patients with PAF was comparable with the control group $(\mathrm{p}>0.05)$.

The group of the patients with PAF was statistically identical to the control group in terms of the accompanying diseases, body mass index, medication for treatment of hypertension and dyslipidemia as well as the presented echocardiographic indicators $(\mathrm{p}>0.05)$ (Table 1).

According to data from the history taking, the mean duration of the AF episodes up to the hospitalization was 8.1 hours (from a minimum of 2 hours to a maximum of 24 hours), the patients being hospitalized most frequently on the $5^{\text {th }}$ hour from the onset of the arrhythmia (Mo $=5$ hours).

\section{Activity of the antioxidant enzyme Glu-6-PhD}

The results obtained from the investigation of Glu- $6 \mathrm{PhD}$ activity are presented in Figure 2. From this, it is obvious that at the baseline in patients with PAF the Glu-6-PhD activity was reduced, as compared to the controls $\left(2.50 \pm 0.10\right.$ vs $2.90 \pm 0.15 \mathrm{nmol} \mathrm{NADP}^{+} \mathrm{min} / \mathrm{mg} \mathrm{Hb}$, $\mathrm{p}<0.05)$. Twenty-four hours following the restoration of the sinus rhythm the lower enzyme activity persisted in comparison to the controls $\left(2.41 \pm 0.09\right.$ vs $\left.2.90 \pm 0.15 \mathrm{nmol} \mathrm{NADP}{ }^{+} \mathrm{min} / \mathrm{mg} \mathrm{Hb}, \mathrm{p}<0.05\right)$. On the twenty-eighth day, no significant differences were established in comparison to the controls $\left(2.63 \pm 0.08\right.$ vs $2.90 \pm 0.15 \mathrm{nmol} \mathrm{NADP}^{+}$ $\min / \mathrm{mg} \mathrm{Hb}, \mathrm{p}>0.05$ ).

\section{Discussion}

There is an increasing body of evidence in modern literature about the importance of Glu-6-PhD for the antioxidant defense
Table 1: Characteristics of the patients with PAF and the healthy controls.

\begin{tabular}{|c|c|c|c|}
\hline & $\begin{array}{l}\text { Patients with } \\
\text { PAF }\end{array}$ & Control group & $P$ value \\
\hline $\begin{array}{l}\text { Number of participants in the } \\
\text { group }\end{array}$ & 51 & 52 & $P>0.05$ \\
\hline Age (years) & $59.84 \pm 1.60$ & $59.50 \pm 1.46$ & $P>0.05$ \\
\hline Men/Women & $26 / 25$ & $26 / 26$ & $P>0.05$ \\
\hline \multicolumn{4}{|l|}{ Accompanying diseases } \\
\hline Hypertension & $37(72.5 \%)$ & $34(65.4 \%)$ & $P>0.05$ \\
\hline Diabetes mellitus type 2 & $3(5.9 \%)$ & $2(3.8 \%)$ & $P>0.05$ \\
\hline (Chronic ulcer disease) & $2(3.9 \%)$ & 0 & $P>0.05$ \\
\hline Status after hysterectomy & $2(3.9 \%)$ & $1(1.9 \%)$ & $P>0.05$ \\
\hline (Benign prostatic hypertrophy) & $1(1.9 \%)$ & 0 & $P>0.05$ \\
\hline (Dyslipidemia) & $4(7.8 \%)$ & $3(5.8 \%)$ & $P>0.05$ \\
\hline Body Mass Index (BMI) & $23.85 \pm 0.46 \mathrm{~kg} / \mathrm{m}^{2}$ & $\begin{array}{c}24.95 \pm 0.45 \\
\mathrm{~kg} / \mathrm{m}^{2}\end{array}$ & $P>0.05$ \\
\hline \multicolumn{4}{|c|}{ Medicaments for Hypertension and Dyslipidemia } \\
\hline Beta blockers & $19(37.3 \%)$ & $17(32.7 \%)$ & $P>0.05$ \\
\hline ACE inhibitors & $15(29.4 \%)$ & $14(26.9 \%)$ & $P>0.05$ \\
\hline Sartans & $11(21.6 \%)$ & $9(17.3 \%)$ & $P>0.05$ \\
\hline Statins & $4(7.8 \%)$ & $3(5.8 \%)$ & $P>0.05$ \\
\hline \multicolumn{4}{|l|}{ Echocardiographic measurements } \\
\hline LVEDD mm & $52.57 \pm 0.58$ & $52.29 \pm 0.57$ & $P>0.05$ \\
\hline LVEF\% & $62.98 \pm 0.70$ & $61.54 \pm 0.58$ & $P>0.05$ \\
\hline LA volume $\mathrm{ml} / \mathrm{m}^{2}$ & $22.81 \pm 0.45$ & $23.82 \pm 0.48$ & $P>0.05$ \\
\hline
\end{tabular}

LA: left atrium; LVEF: left ventricular ejection fraction; LVEDD: left ventricular end-diastolic volume

system of the cell. A study conducted by No et al. on in vitro obtained Glu-6-PhD-deficient fibroblasts, showed a premature ageing of cells resulting from elevated levels of reactive oxygen forms [29]. Pandolfi et al. established that the created cell line totally deficient of Glu-6-PhD, had high percentages of cell death at low oxidant concentration [23]. According to $\mathrm{Xu}$ et al., the reduced activity of the enzyme is sufficient to develop oxidative stress which is a logical consequence of decreased levels of NADPH and GSH [30]. The Glu-6-PhD-deficient vascular endothelial cells obtained under laboratory conditions exhibited elevated levels of reactive oxidative forms and reduced glutation [31]. These and a number of other experimental studies prove that the antioxidant defense system is strongly dependent on the activity of Glu-6-PhD. The partial or total inhibition of this enzyme renders the cells extremely vulnerable to oxidative damage. Any change in the activity of Glu-6-PhD leads to a change in the levels of NADPH, which is of utmost importance for the oxidative balance of the cell and influences inevitably the antioxidant defense.

The results from our study show significantly reduced activity of Glu-6-PhD upon patients' hospitalization (Figure 2). Examined in the context of the above literary data, the established lower baseline values of enzyme activity give us grounds to believe that the patients have lowered levels of antioxidant defense early after the clinical manifestation of the arrhythmia (mean 8.1 hours after the episode onset). It is noteworthy that we obtained these results exactly while examining Glu-6-PhD exactly in erythrocytes. Unlike in the majority of cells having the alternative of PPP for generating NADPH, in the 
Citation: Negreva MN, Penev AP, Georgiev SJ, Alexandrova AA. Changes in Glucose-6-phosphate Dehydrogenase Activity in Paroxysmal Atrial Fibrillation. J Cardiobiol. 2014;2(1): 5.

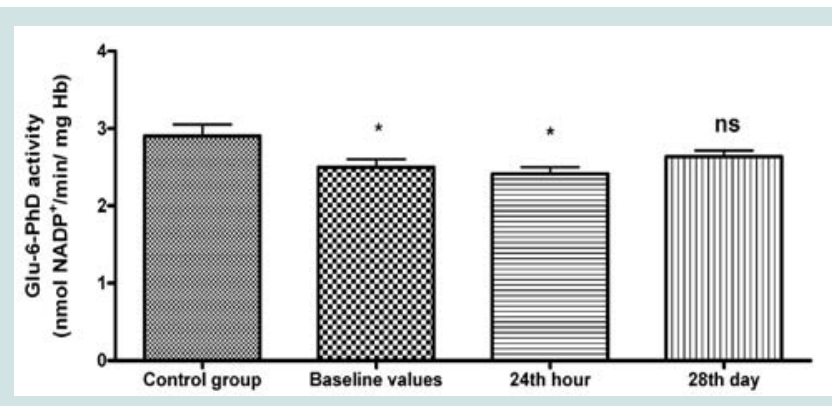

Figure 2: Dynamics of Glu-6-PhD activity (nmol NADP $/ \mathrm{min} / \mathrm{mg}+\mathrm{Hb})$ in the erythrocytes of patients with PAF. The data are presented as $X \pm \mathrm{S} X$ (baseline values - indicators values upon patients' hospitalization; $24^{\text {th }}$ hour - indicator values 24 hours after sinus rhythm restoration; $28^{\text {th }}$ day - indicator values 28 days after sinus rhythm restoration; * $p<0.05$; ns - statistically insignificant difference).

human erythrocytes, the lack of mitochondria determines PPP as the only source of producing NADPH. This makes the antioxidant defense system of the erythrocytes entirely dependent on Glu-6-PhD [32]. Therefore, the low enzyme activity established in our study predetermines the unilateral changes in the antioxidant system of the erythrocytes and a disorder in their oxidant balance.

It is known that the erythrocytes are a reliable model for studying the oxidant status of the whole organism [33]. They are among the first cells which are affected during the development of oxidant stress [34]. Due to this fact, the decreased Glu-6-PhD activity in patients with PAF should not be looked at as an isolated intracellular change but a very early manifestation of the oxidant state of the whole organism.

In addition, exactly the early changes in the enzyme activity (mean 8.1 hours from the onset of the PAF episode), give us grounds to assume that most likely they are closely linked to the mechanisms responsible for the disease manifestation.

The results obtained on the $24^{\text {th }}$ hour after the arrhythmia interruption by medication are of particular interest. The levels of enzyme activity are preserved low in spite of the already restored sinus rhythm. This fact inevitably raises the question about the interrelation between the disease and the persistent changes in the antioxidant defense system. The study in dynamics even in one indicator allows us to assume that the antioxidant system has a bearing on the pathogenesis of PAF, which has been proved for other cardiovascular disease [1-4]. Certainly, the question remains open to a large extent and required further investigation both on the antioxidant system and the oxidant system related to it.

Twenty-eight days after the arrhythmia episode the activity of Glu-6-PhD in patients does not differ significantly from that of the healthy controls. The monitoring of the enzyme activity with time shows that the changes in the antioxidant defense system are preserved for a longer period of time than the clinical manifestations of PAF and their restoration occurs slowly. This fact is indicative for the presence of complex regulatory mechanisms responsible for the recovery of the antioxidant system. Furthermore, a profound study is needed on the importance of the oxidant status affecting the clinical course of the disease.

In conclusion, our study indicated that in the early hours of its clinical manifestation PAF is associated with reduced activity of Glu-6-PhD, which persists after the restoration of the sinus rhythm and increases gradually with time. Having in mind the major role of the enzyme in the oxidative balance of the cell, we can conclude that in essence, the changes in its activity reflect identical changes in the antioxidant defense system. Moreover, their specific dynamics is suggestive of their interrelation to the rhythm disorder. Future studies would allow us to determine the precise role of the antioxidant system in the disease pathogenesis and its importance for its prevention and the treatment of PAF.

\section{References}

1. Heistad DD (2006) Oxidative stress and vascular disease: 2005 Duff Lecture. Arterioscler Thromb Vasc Biol 26: 689-695

2. Pashkow FJ (2011) Oxidative stress and inflammation in heart disease: Do antioxidants have a role in treatment and/or prevention? Int J Inflam 2011: 514623.

3. Fearon IM, Faux SP (2009) Oxidative stress and cardiovascular disease: novel tools give (free) radical insight. J Mol Cell Cardiol 47: 372-381.

4. Higashi Y, Noma K, Yoshizumi M, Kihara Y (2009) Endothelial function and oxidative stress in cardiovascular diseases. Circ J 73: 411-418.

5. Abbasi A, Corpeleijn E, Postmus D, Gansevoort RT, de Jong PE, et al. (2012) Peroxiredoxin 4, a novel circulating biomarker for oxidative stress and the risk of incident cardiovascular disease and all-cause mortality. J Am Heart Assoc 1: e002956.

6. Strobel NA, Fasset RG, Marsh SA, Coombes JS (2011) Oxidative stress biomarkers as predictors of cardiovascular disease. Int J Cardiol 147: 191201.

7. Mocatta TJ, Pilbrow AP, Cameron VA, Senthilmohan R, Frampton CM, et al (2007) Plasma concentrations of myeloperoxidase predict mortality after myocardial infarction. J Am Coll Cardiol 49: 1993-2000.

8. Seet RC, Friedman PA, Rabinstein AA (2011) Prolonged rhythm monitoring for the detection of occult paroxysmal atrial fibrillation in ischemic stroke of unknown cause. Circulation 124: 477-486.

9. Lip GY, Hee FL (2001) Paroxysmal atrial fibrillation. QJM 94: 665-678.

10. Youn JY, Zhang J, Zhang Y, Chen H, Liu D, et al. (2013) Oxidative stress in atrial fibrillation: an emerging role of NADPH oxidase. J Mol Cell Cardiol 62: 72-79.

11. Dudley SC Jr, Hoch NE, McCann LA, Honeycutt C, Diamandopoulos L, et al. (2005) Atrial fibrillation increases production of superoxide by the left atrium and left atrial appendage: role of the NADPH and xanthine oxidases. Circulation 112: 1266-1273.

12. Leftheriotis DI, Fountoulaki KT, Flevari PG, Parissis JT, Panou FK, et al. (2009) The predictive value of inflammatory and oxidative markers following the successful cardioversion of persistent lone atrial fibrillation. Int J Cardiol 135: 361-369.

13. Ramlawi B, Otu H, Mieno S, Boodhwani M, Sodha NR, et al. (2007) Oxidative stress and atrial fibrillation after cardiac surgery: a case-control study. Ann Thorac Surg 84: 1166-1172.

14. Sun XL, Bu PL, Liu JN, Wang X, Wu XN, et al. (2012) Expression of SIRT1 in right auricle tissues and the relationship with oxidative stress in patients with atrial fibrillation. Xi Bao Yu Fen Zi Mian Yi Xue Za Zhi 28: 972-974.

15. Kim YM, Guzik TJ, Zhang YH, Zhang MH, Kattach H, et al. (2005) A myocardial Nox 2 containing NAD(P)H oxidase contributes to oxidative stress in human atrial fibrillation. Circ Res 97: 629-636.

16. Kim YH, Lim DS, Lee JH, Shim WJ, Ro YM, et al. (2003) Gene expression profiling of oxidative stress on atrial fibrillation in humans. Exp Mol Med 35: 336-349.

17. Mihm MJ, Yu F, Carnes CA, Reiser PJ, McCarthy PM, et al. (2001) Impaired myofibrillar energetics and oxidative injury during human atrial fibrillation. Circulation 104: 174-180.

18. Carnes CA, Chung MK, Nakayama T, Nakayama H, Baliga RS, et al. (2001) 
Citation: Negreva MN, Penev AP, Georgiev SJ, Alexandrova AA. Changes in Glucose-6-phosphate Dehydrogenase Activity in Paroxysmal Atrial Fibrillation. J Cardiobiol. 2014;2(1): 5.

Ascorbate attenuates atrial pacing-induced peroxynitrite formation and electrical remodeling and decreases the incidence of postoperative atria fibrillation. Circ Res 89: E32-E38.

19. Lenaerts I, Driesen RB, Hermida N, Holemans P, Heidbüchel H, et al. (2013) Role of nitric oxide and oxidative stress in a sheep model of persistent atria fibrillation. Europace 15: 754-760.

20. Zhang Z, Liew CW, Handy DE, Zhang Y, Leopold JA, et al. (2010) High glucose inhibits glucose-6-phosphate dehydrogenase, leading to increased oxidative stress and beta-cell apoptosis. FASEB J 24: 1497-1505.

21. Banki K, Hutter E, Gonchoroff NJ, Perl A (1999) Elevation of mitochondrial transmembrane potential and reactive oxygen intermediate levels are early events and occur independently from activation of caspases in fas signaling J Immunol 162: 1466-1479.

22. Stanton RC (2012) Glucos-6-phosphate dehydrogenase, NADPH, and cell survival. IUBMB Life 64: 362-369.

23. Pandolfi PP, Sonati F, Rivi R, Mason P, Grosveld F, et al. (1995) Targeted disruption of the housekeeping gene encoding glucose 6-phosphate dehydrogenase (G6PD): G6PD is dispensable for pentose synthesis but essential for defense against oxidative stress. EMBO J 14: 5209-5215.

24. Fico A, Paglialunga F, Cigliano L, Abrescia P, Verde P, et al. (2004) Glucose 6-phosphate dehydrogenase plays a crucial role in the protection from redoxstress induced apoptosis. Cell Death Differ 11: 823-831.

25. World Medical Association Declaration of Helsinki (2008) Ethical principles for medical research involving human subjects. $59^{\text {th }}$ WMA General Assembly. Seoul.

26. Bellandi F, Cantini F, Pedone T, Palchetti R, Bamoshmoosh M, et al. (1995)
Effectiveness of intravenous propafenone for conversion of recent-onset atrial fibrillation: a placebo-controlled study. Clin Cardiol 18: 631-634.

27. Bianconi L, Mennuni M (1998) Comparison between propafenone and digoxin administered intravenously to patients with acute atrial fibrillation. PAFIT-3 Investigators. The Propafenone in Atrial Fibrillation Italian Trial. Am J Cardio 82: 584-588.

28. Cartier P, Leroux JP, Marchand JC (1967) Methods of determination of tissue glycolytic enzymes. Ann Biol Clin (Paris) 25: 109-136.

29. Ho HY, Cheng ML, Lu FJ, Chou YH, Stern A, et al. (2000) Enhanced oxidative stress and accelerated cellular senescence in glucose-6-phosphate dehydrogenase (G6PD)-deficient human fibroblasts. Free Radic Biol Med 29: 156-169.

30. Xu Y, Zhang Z, Hu J, Stillman IE, Leopold JA, et al. (2010) Glucose-6phosphate dehydrogenase-deficient mice have increased renal oxidative stress and increased albuminuria. FASEB J 24: 609-616.

31. Leopold JA, Cap A, Scribner AW, Stanton RC, Loscalzo J (2001) Glucose6-phosphate dehydrogenase deficiency promotes endothelial oxidant stress and decreases endothelial nitric oxide bioavailability. FASEB J 15: 17711773.

32. Cappellini MD, Fiorelli G (2008) Glucose-6-phosphate dehydrogenase deficiency. Lancet 371: 64-74.

33. Arbos KA, Claro LM, Borges L, Santos CA, Weffort-Santos AM (2008) Human erythrocytes as a system for evaluating the antioxidant capacity of vegetable extracts. Nutr Res 28: 457-463.

34. Pandey KB, Rizvi SI (2011) Biomarkers of oxidative stress in red blood cells. Biomed Pap Med Fac Univ Palacky Olomouc Czech Repub 155: 131-136. 